\title{
The Rapid Healing of Plantar Ulcers
}

\author{
GILBERT B. R. WALKEY, M.B.B.s., F.R.c.s. \\ Surgeon, The Catherine Booth Hospital \\ and \\ HARRY W. WILLIA MS, F.R.c.s. (Edin) \\ Head of the Reconstructive Surgical Unit, The Catherine Booth Hospital, Nagercoil, S. India
}

\section{Plantar Ulcers - Speedy Healing}

The problem of the plantar ulcer of leprosy has been the subject of a number of scientific papers in recent years. Price ${ }^{\mathrm{I}} \mathrm{I}$ has restricted the use of the title to ulcers occuring in the anaesthetic but mobile foot thus differentiating ulcers occurring in feet with fixed deformities. It has been stressed that the second group demands surgery directed to the deformity as a prequisite to healing of the ulcer, and in the former group the provision of protective footwear following the healing of the ulcer. For the actual healing of the ulcer only one approach has been advocated by the many writers on this subject, namely, complete rest to permit a natural healing by scar tissue. The practical detail varies from bed rest with normal local measures to clean the ulcer, to the use of plaster of paris casts or its more elaborate descendent, the Karagiri boot. Andersen ( ${ }^{2}$ ) as basis for this method, quotes Trueta, who popularised the plaster cast immobilisation of osteomyelitis in contrast to the frequent dressings current until I935. Contemporary with Trueta, Gillies and the then, small group of plastic surgeons shewed that many indolent ulcers (such as varicose ulcers then commonly treated by local applications and support) could be healed quickly by excision, which included the hard fibrous bed of the ulcer, and the application of a split skin graft.

The attention of one of us (H.W.W.) was drawn to the problems of leprosy that might be amenable to plastic surgery by Paul Brand in 1956. A visit to the nearest leprosarium gave the immediate impression of plantar ulcer as the commonest cause of disability amongst leprosy patients. This impression is confirmed by all subsequent experience and is quoted by Languillon ( 3 ) who observed that among 3,ooo leprosy patients examined 403 patients had I , o49 perforating plantar ulcers. The immediate reaction of the plastic surgeon was to excise and graft. At this time it was generally held that split skin would not stand up to hard wear and was therefore unsuitable to palmar or plantar surfaces. One article however had appeared by Wynn Williams (4) in which a split skin graft applied to the plantar surface had not needed to be replaced by full thickness skin. The first leprosy ulcer treated by this method was a large one of the heel. This graft took completely and was seen regularly for three years without evidence of breakdown (12). A small series completed in 1958 shewed that two thirds of ulcers treated in this way were healed in a fortnight.

At this point it might have been claimed that a specialised technique was involved and therefore the method unsuitable for wide application. A second series published in r 963 shewed an improved percentage cure and this time the surgery had been shared with a junior registrar. The present series has been largely the work of a third general surgeon, but again the results are similar.

RESULTS

\begin{tabular}{lccc} 
& $\begin{array}{c}\text { Number } \\
\text { of ulcers }\end{array}$ & $\begin{array}{c}\text { Healed } \\
\text { Ist Opn. }\end{array}$ & $\begin{array}{c}\text { Healed } \\
\text { 2nd Opn. }\end{array}$ \\
Present series & 62 & 44 & 7 \\
Published in I963 $\left({ }^{10}\right)$ & 45 & 39 & 4 \\
Published in I959 $\left.{ }^{11}\right)$ & 2 I & I 3 & 8 \\
\cline { 2 - 4 } & I 28 & 96 & I9
\end{tabular}

To recapitulate the method:

I Complicated ulcers i.e. with underlying osteomyelitis or neuropathic joint must be dealt with on the usual lines.

2 The ulcer is cleaned with Eusol and a Eusol pack is applied for 24 hours before operation.

3 The ulcer is cleaned with Cetavlon I \% and 
the whole ulcer - sides and floor, is completely excised in one piece. A THIN split skin graft is cut from the thigh or calf, spread on sterile vaseline gauze and applied to the raw area followed by gauze wrung out in normal saline, which presses the graft into the depression evenly*.

4 Cotton wool and a pressure bandage is applied. Crepe bandages are a luxury: we use, knitted cotton bandages which wash and wear.

5 First dressing is done after io days, care being taken not to pull on the graft in removing the dressings. During the ten days, patients can get around on crutches and work in occupational therapy classes.

\section{DISGUSSION}

I This is the most expeditious method of healing a plantar ulcer and is applicable to ulcers large and small in Groups I or II of Lennox (s) but not a complicated ulcer (see below). Writers describing the plaster cast technique say that most ulcers should be healed in six weeks $\left({ }^{6}\right)$ though treatment may be continued for several months in some cases. By this grafting technique seventy five per cent of ulcers should be healed in 20 days.

*In earlier cases, the graft was applied over a Stent impression of the ulcer. This is a good method, but saline gauze firmly and quickly applied works just as well. The Stent mould should be removed by the $5^{\text {th }}$ day.
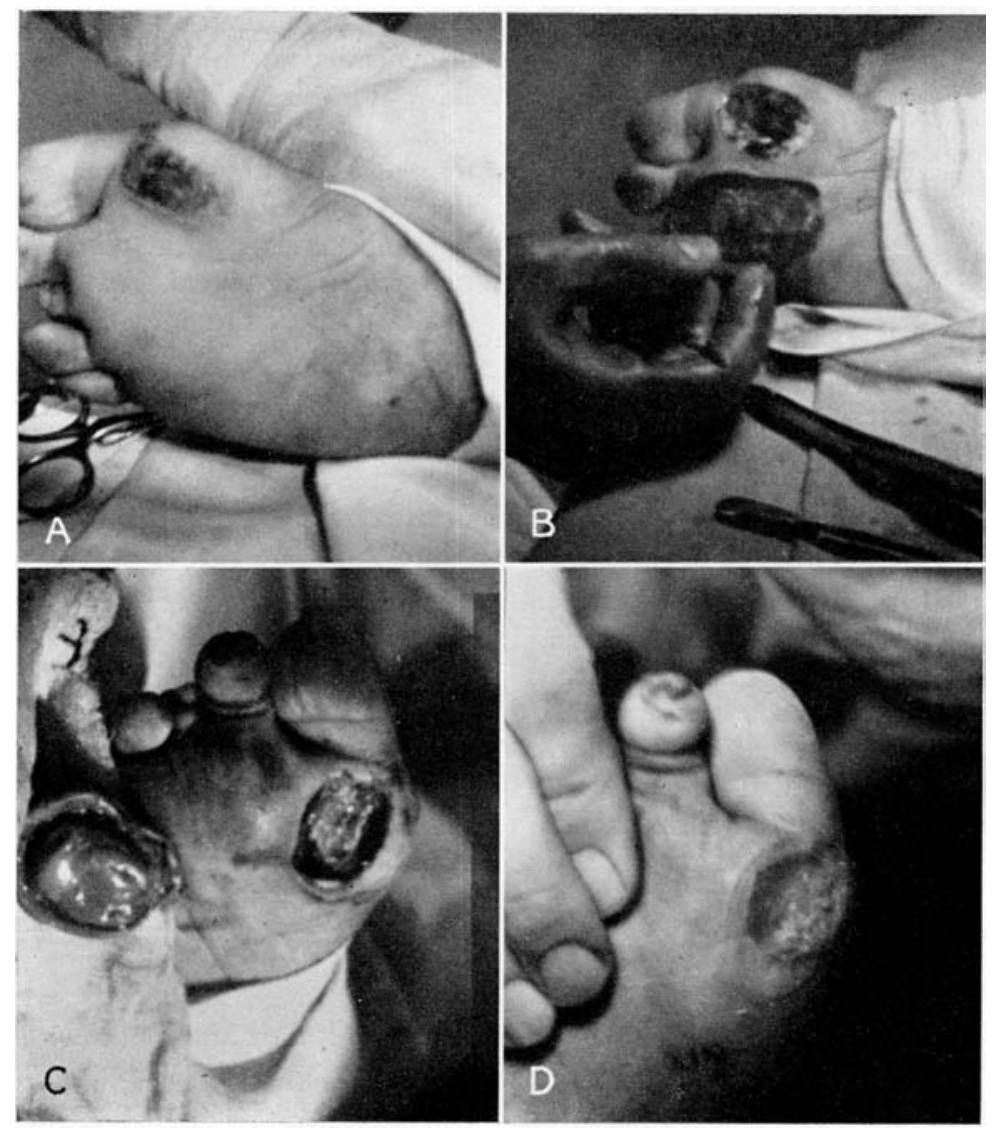
A. Ulcer of plantar surface.
B. Excision and Stent impression taken.
C. Graft at removal of mould five days later.
D. Healed ulcer thirty days later.

\section{Leprosy Review}


2 The technique is simple and any medical officer can quickly learn it. Here are a few important tips:

(a) The bed to be grafted is similar to that in a varicose ulcer, giving a brisk capillary haemorrhage. A hot saline swab should be firmly applied by an assistant and only withdrawn when the graft and dressings are all ready for speedy application. Blood clot is death to a graft!

(b) The thin skin graft can be easily cut with any standard graft knife. We use a Humby pattern. However, with practice an intradermal injection of local anaesthetic can be made into the thigh or calf raising a rigid plaque of skin. With a board to flatten, a graft large enough for an average ulcer can be cut with a Bard-Parker blade.

(c) After the first dressing we apply a sterile vaseline gauze and bandage for another week. This isn't vital, but patients feel more confident if the newly grafted area is protected. Do not despair of a 'poor take' at ten days. The second dressing often shews complete healing.

3 Price describes the plantar ulcer as 'a chronic ulceration of the anaesthetic foot characterized by a marked tendency to recurrence' ( 7 ) and Andersen $\left(^{8}\right)$ speaks of an 'evil cycle of scar ulcer - scar'. Rigid scars are notoriously unstable in weight bearing areas. The technique described here removes the hard fibrous tissue and a split graft developes subcutaneous tissue which soon fills the depression leaving a mobile graft area. We have been impressed by the fact that an ulcer of $\frac{1}{2}$ in. diameter is commonly $\frac{3}{4}$ in. or even I in. diameter, for the heaped up cornified margin is undermined all round by a granulation-lined cavity.

4 It is emphasized that this method does not obviate the need for proper footwear and orthopaedic procedures indicated in second deformities.

\section{S UMMAR Y}

A technique for excision and grafting of plantar ulcers is described which gives healing in 20 days in $\frac{2}{3}$ of all cases. Over the total this gives a percentage of 75 per cent healed at the first operation and 90 per cent after two. In the later case the period has been four to five weeks. Of the remaining io per cent a few were complicated cases at first missed but several have been large deep lesions of the heel of the type described by Lennox $\left({ }^{9}\right)$. In these we have eventually secured healing. It must also be added that even when counted unsuccessful at the first attempt, the size is usually much reduced by partial take.

All of the early cases in this series were transferred from leprosaria but as the programme has become known patients have walked into outpatients to disclose ulcers of many years standing hidden by footwear. Two are worthy of mention.

Case I A.B. This man had maintained a good position in a Government Service by taking maximum sick leave each year and his shoes hid one toeless foot with an ulcer 2 in. broad extending right across the heads of the metatarsals. He went home healed but returned next year with a small breakdown at one end. This was grafted and better shoes were made. He returned again this year for part of his holiday. The ulcer has not reappeared and his medical officer certified a well healed foot permitting promotion to a higher grade.

Case 2 B.C. Again this was an anterior arch ulceration of ten years duration and healed at the first operation permitting discharge in 30 days by which time shoes with microcellular rubber in-sole and metatarsal bar had been fitted.

\section{REFERENGES}

I PRICE, E. W. (I964). Leprosy Rev., 35, 4A. 267.

2 Anderson, Johs G. (I 964). Leprosy Rev., 35, 4A. 25 I.

3 LANguillon, J ( ( 964). Leprosy Rev., 35, 4A. 239.

4 Wynn-williams, D. (I953). Br. J of Plastic Surgery, Vol. $V I$, No. 2, 123.

5 Lennox, w. M. ( 1 964). Leprosy Rev., 35, 4A, 245.

6 ANDERson, JOHs G. (I964). Leprosy Rev., 35, 4A. 25 I.

7 Price, E. w. (I 959). Leprosy Rev., $X X X, \mathbf{9 8 ,}$ i 05.

8 Anderson Johs G. (I 964). Leprosy Rev., 35, 4A. 25 I

9 LENnox, w. M., ( 1964 ). Leprosy Rev., 35, 4A. 245.

io williams, H. w. (I 959). British Journal of Plastic Surgery, Vol. XI, No. 4. p. 309.

I I williams, H. w. (I 964). Indian Journal of Surgery. Vol. $X X V I ;, \mathcal{N} o$. I. p. 64 .

I 2 williams, H. w. (I957). Indian Journal of Surgery, Vol. $X I X, \mathcal{N}$. I. p. 2. 